\title{
A revision of Malaxella Ding \& Hu (Hemiptera: Delphacidae) with description of a new species
}

\section{DAO-ZHENG QIN ${ }^{1} \&$ YA-LIN ZHANG ${ }^{2}$}

Key Laboratory of Plant Protection Resources and Pest Management of Ministry of Education, Entomological Museum, Northwest A \& F University, Yangling, Shaanxi Province, 712100, China. E-mail: ${ }^{1}$ qindaozh0426@yahoo.com.cn

${ }^{2}$ corresponding author.E-mail: yalinzh@yahoo.com.cn

\begin{abstract}
The endemic delphacid genus Malaxella Ding \& Hu (Hemiptera: Fulgoromorpha: Delphacidae) from China is reviewed and two species, including a new species, M. tetracantha n. sp. (southern China: Hainan) are recognized. The genus and the species are described and illustrated. A key to the species of the genus is also provided.
\end{abstract}

Key words: Tropidocephalini, taxonomy, Auchenorrhyncha, Fulgoromorpha, planthopper

\section{Introduction}

The genus Malaxella was established by Ding \& Hu (in Ding et al. 1986) for M. flava Ding \& Hu from Yunnan and Guangdong, China. It belongs to the tribe Tropidocephalini in the subfamily Delphacinae and is easily recognized from other genera of the tribe by the orange body color without markings, by the vertex having percurrent submedian carinae uniting at apex, and by the asymmetrical opening of the male pygofer. Chen (2003) studied the diversity of Tropidocephalini from China and considered Malaxa aurunca Yang \& Yang, 1986 as a junior synonym of Malaxella flava so at present only the type species is known. In this paper, we redescribe the genus and the type species, describe a second species and provide a key to aid in recognition of the species.

\section{Materials and methods}

The specimens studied in this study are deposited in the Entomological Museum, Northwest A \& F University, Yangling, Shaanxi, China (NWAFU). The body measurements of macropters are from apex of vertex to tip of abdomen. All measurements are in millimeters $(\mathrm{mm})$. The methods and morphological terminology in this paper follow those of Ding (2006).

\section{Results}

\section{Malaxella Ding \& Hu}

Malaxella Ding \& Hu in Ding et al., 1986: 419

Type species. Malaxella flava Ding \& Hu, in Ding et al. 1986. by original designation 
Redescription. Small-sized, yellow to orange delphacids, length of male 1.8-2.2 mm, female 2.1-2.5 mm.

Head including eyes distinctly narrower than pronotum (Figs 1,13). Vertex quadrate, slightly shorter in midline than broad at base, submedian carinae originating near middle of lateral carinae, percurrent and uniting at apex, in dorsal view lateral carinae of vertex concave, expanded anteriad and behind eyes (Figs 1, 13), in lateral view meeting lateral carinae of frons with obtuse angle at fastigium (Figs 3, 15). Y-shaped carina with common stem absent. Frons relatively long, slightly expanded just above the ocelli, longer in midline than wide at widest part (2.15-2.64: 1) (Figs 2, 14). Antennae cylindrical, very long, reaching or surpassing apex of clypeus, segment I longer than wide at apex (2.1-2.7: 1), shorter than segment II (0.300.33: 1) (Figs 2, 14). Pronotum nearly equal to median length of vertex, lateral carinae not reaching posterior margin (Figs 1, 13). Mesonotum medially longer than vertex and pronotum together (0.56-0.64: 1) (Figs 1, 13). Tegmina elongate, much longer than abdomen, apical margin rounded (Figs 4, 16). Spinal formula of hind leg 5-6-4. Post-tibial spur large and thick, concave on inner suface, without teeth on interior margin but with a small apical tooth.

Male genitalia with opening of pygofer asymmetrical, bearing spine-like processes on ventral margin (Figs 5, 17). Diaphragm membranous (Figs 5, 17). Parameres long, asymmetrical (Figs 5, 17). Aedeagus tubular, curved (Figs 12, 22), gonopore large (Figs 9, 21). Suspensorium fused with the aedeagus near its base (Figs 9,21). Male anal segment ring-like, left laterodistal angle strongly produced ventrocaudad into a stout processes, basally bearing a cluster of hair-like setae (Figs 5, 17).

Remarks. Both the genera Malaxella and Malaxa Melichar, 1913 are similar (Ding \& Hu, 1986; Chen et al., 2006) in having quadrate vertex (Figs 1, 13), long antennae (Figs 2, 14), pronotum with lateral carinae not attaining hind margin (Figs 1, 13), male pygofer having ventral processes, tubular aedeagus and the anal segment strongly produced at left laterodistal angle. However, Malaxella differs from Malaxa in the following combination of characters: in Malaxella the general body color is yellow to orange (often with blackish brown markings in Malaxa); the submedian carinae of vertex percurrent and uniting at apex (uniting before apex of vertex in Malaxa), lateral carinae of vertex distinctly expanded anteriad (nearly parallel or slightly convergent anteriad in Malaxa); frons with lateral carinae widest at eyes (lateral carinae nearly parallel or widest at apex in Malaxa); the asymmetrical opening of pygofer, processes on the ventral margin and parameres (all of them symmetrical in Malaxa); parameres simple (forked or with apical process at apex in Malaxa); a cluster of hairlike setae at the base of the left laterodistal process of male anal segment (bare in Malaxa).

Distribution. Species of Malaxella are currently known only from southern China (Yunnan, Guizhou, Fujian, Taiwan, Guangdong and Guangxi).

\section{Key to species of Malaxella (male)}

1 Male pygofer with 2 spine-like processes on ventral margin; gonopore of aedeagus subbasal (Fig. 9)

M. flava Ding \& Hu

- Male pygofer with 4 spine-like processes on ventral margin; gonopore of aedeagus subapical (Fig. 21). M. tetracantha $\mathbf{n}$. sp.

\section{Malaxella flava Ding \& Hu, 1986}

(Figs. 1-12)

Malaxella flava Ding \& Hu in Ding et al. 1986: 419.

Malaxa aurunca Yang \& Yang, 1986: 59, synonymised by Chen, 2003: 820.

Description. Body length: macropterous male 1.85-1.92 mm ( $\mathrm{n}=4)$; macropterous female $2.10-2.33 \mathrm{~mm}$ $(n=9)$. 

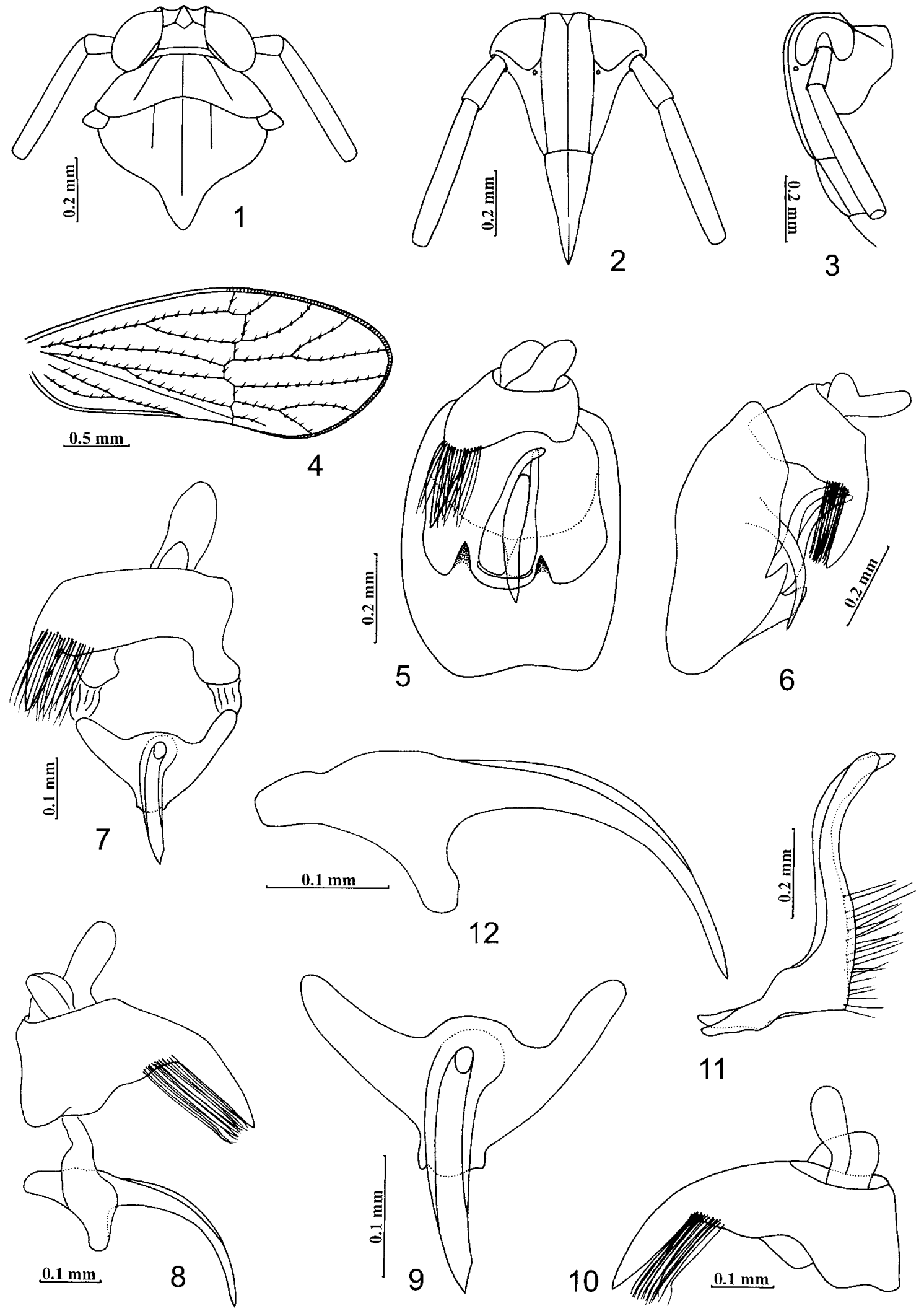

\section{1}

FIGURES 1-12. Malaxella flava Ding \& Hu. 1, head and thorax, dorsal view; 2, frons and postclypeus; 3, head and pronotum, left lateral view; 4, right tegmen, macropterous male; 5, male genitalia, caudal view; 6, same, left lateral view; 7, anal segment, suspensorium and aedeagus complex, caudal view; 8, same, left lateral view; 9, suspensorium and aedeagus complex, caudal view; 10, anal segment, right lateral view; 11, parameres, left lateral view; 12, aedeagus, left lateral view. 

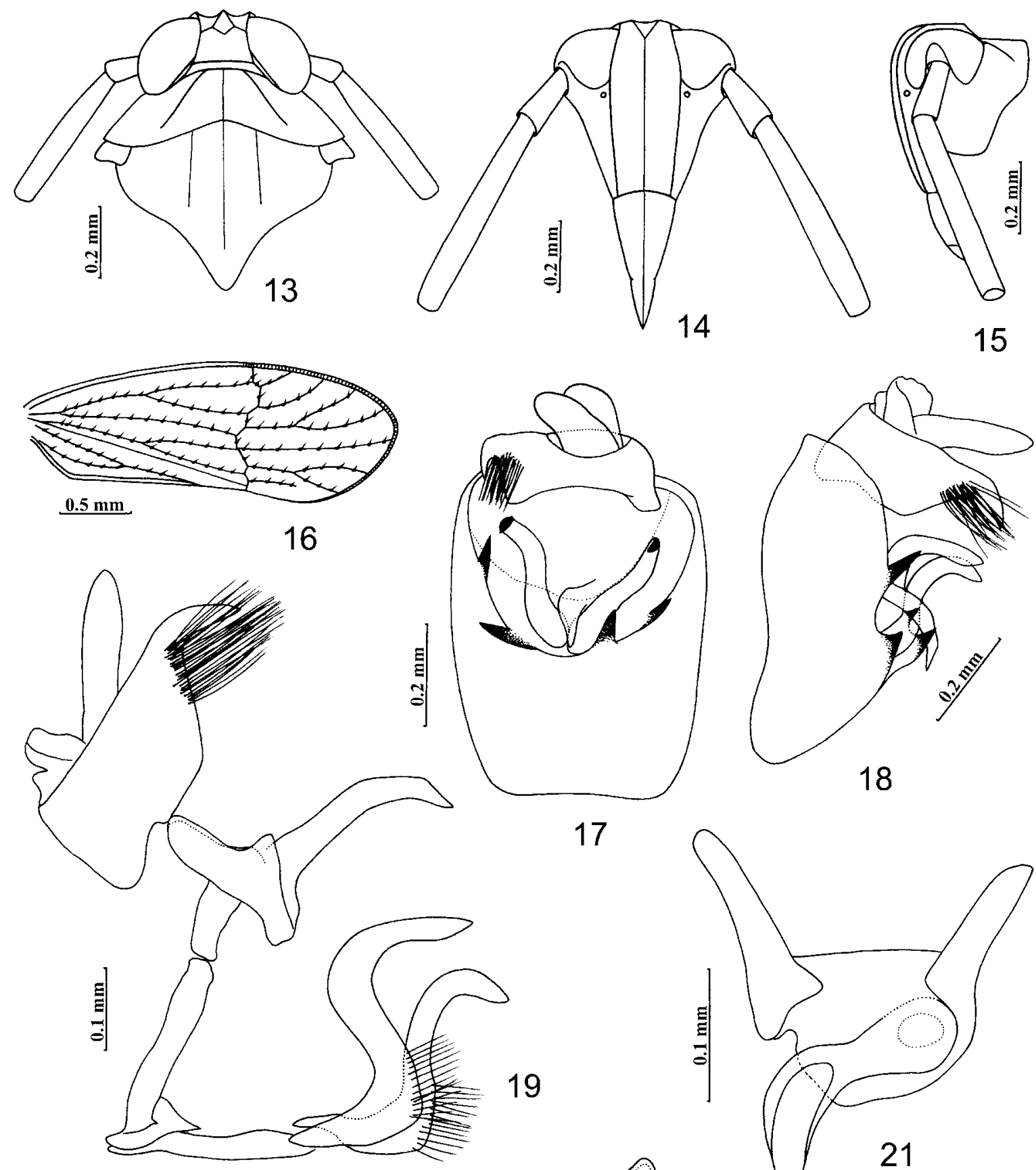

18

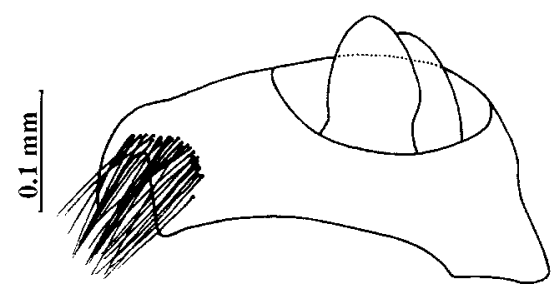

20

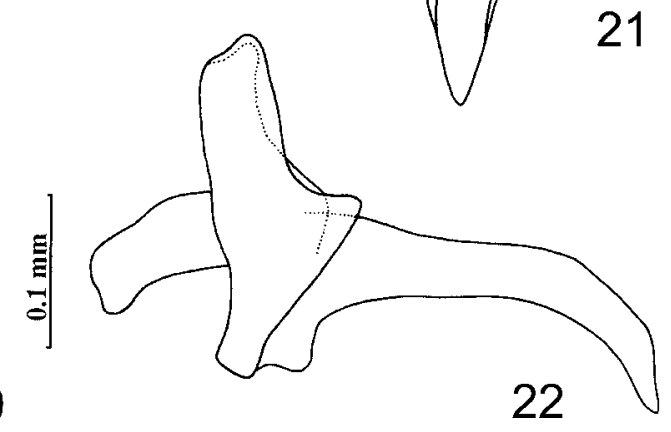

FIGURES 13-22. Malaxella tetracantha $\mathbf{n}$. sp., 13, head and thorax, dorsal view; 14, frons and postclypeus; 15, head and pronotum, left lateral view; 16, right tegmen, macropterous male; 17, male genitalia, caudal view; 18, same, left lateral view; 19, anal segment, suspensorium and aedeagus complex and parameres, left lateral view; 20, anal segment, right lateral view; 21, suspensorium and aedeagus complex, caudal view; 22, same, left lateral view. 
Color. General color orange yellow. Eyes greyish. Ocelli red brown. Antennae with apex of segment I and base of segment II reddish, in some specimens the antennae reddish orange except the apex of segment II orange yellow. Tegmina subhyaline, veins concolorous, macropterous forewings with fine, brownish hairs. Dorsum and venter of abdomen orange. Male pygofer with ventral processes, apex of parameres and left laterodistal process of male anal segment blackish brown. Female ovipositor brownish orange.

Head. Including eyes narrower than pronotum about 0.75: 1 (Fig. 1). Vertex longer medially than wide at base (about $0.86: 1)$, slightly narrower at apex than at base $(0.85: 1)$. Frons in midline longer than maximum width (2.4: 1), widest at level of base of eyes and continuing nearly straight and converging towards apex of frons (Fig. 2). Postclypeus and anteclypeus together approximately 0.86 of the length of the frons (Fig. 2), in profile shallowly convex medially (Fig. 3). Postclypeus distinctly wider than frons at apex (Fig. 2). Antennae reaching apex of clypeus, segment I about 2.4 times longer than apical width, shorter than segment II about 1: 3.0 (Fig. 2).

Thorax. Pronotum in midline slightly shorter than length of vertex about $0.88: 1$, posterior margin concave medially, lateral carinae slightly sinuate, diverging but not reaching posterior margin (Fig. 1), pronotum width $0.74-0.75 \mathrm{~mm}$, length $0.15-0.18 \mathrm{~mm}$. Mesonotum medially ca. 1.6 times longer than vertex and pronotum together, lateral carinae slightly diverging caudad, lateral and median carina obsolete apically (Fig. 1). Tegmina in macropterous form 3.20-3.48 mm long, surpassing tip of abdomen by one third of their total length, widest at apical fourth (Fig. 4). Legs with tibia quadrate in cross section, metatibia $0.85-0.93 \mathrm{~mm}$ long, metabasitarsus $(0.28-0.33 \mathrm{~mm})$ nearly as long as tarsomere $2(0.13-0.15 \mathrm{~mm})+3(0.19-0.22 \mathrm{~mm})$ combined, posttibial spur $(0.25-0.28 \mathrm{~mm})$ slightly shorter than metabasitarsus.

Male genitalia. Pygofer in lateral view slightly longer ventrally than dorsally, laterodorsal angles not produced caudad (Fig. 6), in posterior view male pygofer with opening asymmetrical, bearing two spine-like processes on midventral margin (Fig. 5). Diaphragm membranous (Fig. 5). Parameres asymmetrical, fairly long, contiguous at base and apex reaching to the level of anal segment, the left paramere longer than the right one (Figs 5, 11). Suspensorium fused with the aedeagus near its base (Figs 7-9). Aedeagus produced ventrally near the base, then curved and gradually narrowing towards acuminate apex, in caudal view aedeagus arising from the middle of the aedeagus-suspensorium complex, slightly curved to the left, gonopore large, opening subbasally on dorsal surface (Figs 7, 9). Male anal segment large, left laterodistal angle with a cluster of hairlike setae from which emerges a stout, ventrally directed process with a pointed apex (Figs 5-8, 10).

Specimens examined. 4 males 7 females, China: Guangxi Autonomous Region, Guilin, 28 Aug. 1974, coll. Yao Zhou \& Zheng Lu; 1 female, Hainan Province, Nada, 23-24 Aug. 1974, coll. Yao Zhou \& Zheng Lu; 1 female, Hainan Province, Jianfengling, 18 May 1983, coll. Yalin Zhang (NWAFU).

Distribution. Southern China (Yunnan, Guizhou, Hainan, Taiwan, Guangdong and Guangxi).

\section{Malaxella tetracantha $\mathbf{n} . \mathbf{s p .}$}

(Figs. 13-22)

Description. Body length: macropterous male 2.10-2.23 mm ( $\mathrm{n}=7)$; macropterous female 2.15-2.54 mm $(\mathrm{n}=8)$.

Colour. General color yellowish orange. Eyes and ocelli red brown. Antennae and abdomen reddish. Tegmina subhyaline, veins concolorous, macropterous forewings ornamented with fine, brownish hairs. Male pygofer with ventral processes, parameres and left laterodistal process of male anal segment blackish brown. Female ovipositor tawny to blackish brown.

Head. Including eyes narrower than pronotum (0.74: 1) (Fig. 13). Vertex longer medially than wide at base (0.84: 1), slightly narrower at apex than at base (0.86: 1) (Fig. 13). Frons in midline longer than maximum width (2.6: 1), widest at level of base of eyes and continuing nearly straight and slightly converging towards apex of frons (Fig. 14). Postclypeus and anteclypeus together approximately 0.88 of the length of frons (Fig. 14), in profile shallowly convex medially (Fig. 15). Postclypeus distinctly wider than frons at apex 
(Fig. 14). Antennae surpassing apex of anteclypeus, segment I about 2.5 times longer than apical width, shorter than segment II about 1: 3.1 (Fig. 14).

Thorax. Pronotum in midline slightly shorter than length of vertex (0.92: 1), posterior margin concave medially, lateral carinae slightly sinuate, diverging but not reaching posterior margin (Fig. 13), pronotum width $0.79-0.88 \mathrm{~mm}$, length $0.18-0.20 \mathrm{~mm}$. Mesonotum medially ca. 1.6 times longer than vertex and pronotum together, lateral carinae slightly diverging caudad, lateral and medial carinae obsolete apically (Fig. 13). Tegmina in macropterous form 3.53-3.75 mm long, surpassing tip of abdomen by one third of their total length, widest at apical fourth (Fig. 16). Legs with tibia quadrate in cross section, metatibia $0.90-0.93 \mathrm{~mm}$ long, metabasitarsus $(0.30-0.31 \mathrm{~mm})$ slightly shorter than tarsomere $2(0.15-0.18 \mathrm{~mm})+3(0.21-0.28 \mathrm{~mm})$ combined, posttibial spur $(0.25-0.28 \mathrm{~mm})$ slightly shorter than metabasitarsus.

Male genitalia. Pygofer in lateral view slightly longer ventrally than dorsally, laterodorsal angles not produced (Fig. 18), in posterior view male pygofer with opening asymmetrical, bearing 4 spine-like processes on the mid and ventral margins (Fig. 17). Diaphragm membranous (Fig. 17). Parameres long, asymmetrical, contiguous at the base and apex curved, not reaching to the level of anal segment in posterior view (Fig. 17). Suspensorium fused with the the aedeagus near to its base (Figs 19, 21, 22). Aedeagus produced ventrally near the base, nearly straight in middle portion, apically curved and sharply narrowed to pointed tip (Figs 19, 22), in caudal view aedeagus sinuate and arising from right side of aedeagus-suspensorium complex, gonopore large, opening subapically on dorsal surface (Fig. 21). Male anal segment large, left laterodistal angle with a cluster of hair-like setae from which emerges a stout, ventrally directed process with a pointed apex (Figs 1720).

Type material. Holotype male (macropterous), China: Fujian Province, Wuping County, 1 Sept. 2008, 320 m, coll. Lei Zhang (NWAFU). Paratypes. China: 4 males 6 females, same data as holotype; 1 female, coll. Bin Xiao, other data as holotype; 1 male, Hainan Province, Bawangling, 15 May 2008, 126 m, coll. Qiulei Men, light trap; 1 female, Hainan Province, Bawangling, 17 May 2008, 176 m, coll. Qiulei Men, light trap; 1 male, Hainan Province, Liangyuan, 31 May 1983, coll. Yalin Zhang, light trap (NWAFU).

Etymology. The name is derived from the Latin word "tetracanthus" (four processes) which refers to the male pygofer with 4 spine-like processes on ventral margin.

Distribution. Southern China (Fujian and Hainan Provinces).

Remarks. This species can be differentiated from Malaxella flava by the four spine-like process of the male pygofer (M. flava has 2 spine-like processes); the aedeagus in lateral aspect nearly straight medially (curved in M. flava), in caudal view the aedeagus sinuate and arising from the right side of the aedeagussuspensorium complex (in $M$. flava the aedeagus is slightly curved and arises from the middle of the aedeagus-suspensorium complex), the gonopore opening is subapical on dorsal surface (in M. flava the gonopore opening is subbasal).

\section{Acknowledgments}

We wish to express sincere thanks to Dr. C. A. Viraktamath, The University of Agricultural Sciences, Bangalore, India, for helpful review of the manuscript and suggesting improvements. This study was supported by "the Pilot Project of Standardized Curation, Data Integration and Resource Sharing of Zoological Collections by Ministry of Science and Technology of China (2005DKA21402)," and "Northwest A \& F University Grant for Young Academic Talent (01140301)" and "Special Science Program of NWAFU (08080253)". 


\section{References}

Chen, X.S. (2003) Key to genera of the tribe Tropidocephalini (Hemiptera: Fulgoroidea: Delphacidae) from the People's Republic of China, with description of a new genus. The Canadian Entomologist, 135, 811-821.

Chen, X.S., Li, X.F., Liang, A.P. \& Yang, L. (2006) Review of the bamboo delphacid genus Malaxa Melichar (Hemiptera: Fulgoroidea: Delphacidae) from China. Annales Zoologici (Warszawa), 56 (1), 159-166.

Ding, J.H., Yang, L.F. \& Hu, C.L. (1986) Descriptions of new genera and species of Delphacidae attacking bamboo from Yunnan Province, China. Acta Entomologica Sinica, 29 (4), 415-425.

Ding, J.H. (2006) Fauna Sinica. Insecta Vol. 45. Homoptera Delphacidae. Editorial Committee of Fauna Sinica, Chinese Academy of Science. Beijing, China. Science Press. 776 pp.

Yang, J.T. \& Yang, C.T. (1988) Delphacidae of Taiwan (I) Asiracinae and the tribe Tropidocephalini (Homoptera: Fulgoroidea). Taiwan Museum Special Publication Series, 6, 1-79. 